\title{
A new model of fuel spray shape at early stage of injection in a marine diesel engine
}

\author{
Joanna Grochowalska \\ Institute of Naval Architecture and Ocean Engineering, \\ Faculty of Mechanical Engineering and Ship Technology, \\ Gdansk University of Technology, Gdansk, Poland \\ Piotr Jaworski and Łukasz Jan Kapusta \\ Institute of Heat Engineering, \\ Department of Power and Aeronautical Engineering, \\ Warsaw University of Technology, Warsaw, Poland, and \\ Jerzy Kowalski \\ Institute of Naval Architecture and Ocean Engineering, \\ Faculty of Mechanical Engineering and Ship Technology, \\ Gdansk University of Technology, Gdansk, Poland
}

\begin{abstract}
Purpose - In the cylinders of a marine diesel engine, self-ignition occurs in a very short time after the fuel injection into the combustion chamber. Therefore, this paper aims to develop a model of diesel fuel spray for the early stage of fuel spray in the marine diesel engine. The main technical aspects such as nozzle diameter of the marine engine injector and backpressure in the combustion chamber were taken into consideration.

Design/methodology/approach - In this paper, laboratory experimental studies were carried out to determine parameters of fuel spray in an early stage of injection in the marine diesel engine. The optical measuring Mie scattering technique was used to record the fuel injection process. The working space was a constant volume chamber. The backpressure parameters in the constant volume chamber were the same as during the operation of the marine diesel engine. Based on the experimental studies and important Hiroyasu and Arai models of fuel spray presented in literature was proposed new model of fuel spray parameters for marine diesel injectors.

Findings - In this paper, the proposed new model of the two main parameters described fuel spray evolution": new model of spray tip penetration (STP) and spray cone angle (SCA). New model propagation of fuel STP in time was included the influence of nozzle diameter and backpressure. The proposed model has a lower error, about $15 \%-34 \%$, than the model of Hiroyasu and Arai. Moreover, a new model of the evolution over time of the SCA is developed.

Research limitations/implications - In the future research of fuel spray process must be taken influence of the fuel temperature. Diesel fuel has a different density and viscosity in dependence of fuel temperature. Therefore are predicted of the expansion about influence of fuel temperature, new model of fuel spray for a marine diesel engine. The main limitations occurring in the research are not possible to carry out the research while real operation marine diesel engine.
\end{abstract}

(C) Joanna Grochowalskam, Piotr Jaworski, Lukasz Jan Kapusta and Jerzy Kowalski. Published by Emerald Publishing Limited. This article is published under the Creative Commons Attribution (CC BY 4.0) licence. Anyone may reproduce, distribute, translate and create derivative works of this article (for both commercial and non-commercial purposes), subject to full attribution to the original publication and authors. The full terms of this licence may be seen at http://creativecommons.org/ licences/by/4.0/legalcode
2345

New model of fuel spray

Received 18 May 2021

Revised 3 September 2021 Accepted 13 September 2021 
$\mathrm{HFF}$

32,7

Originality/value - An experimental test was carried out for a real fuel injector of a marine diesel engine. Design parameters and fuel injection parameters were selected on the basis of the actual one. In the literature, SCA is defined as a constant parameter for the specific preliminary data. A new model for the early stage of fuel spray of SCA propagation in time has been proposed. The early stage of fuel spray is especially important, because in this time comes in there to fuel self-ignition.

Keywords Diesel fuel spray, Marine diesel engine, Model of fuel spray, Spray cone angle, Spray tip penetration

Paper type Research paper

\section{Introduction}

Diesel engines are commonly used sources of mechanical energy on ships. Typically, there are lowspeed two-stroke diesel engines and medium-speed four-stroke ones. The source of energy in such engines is the combustion process of diesel oil or heavy fuel oil. Because of the large dimensions of marine engines and long periods of operation (many weeks of continuous operation), the air pollution may be considerable. The International Maritime Organization has established the Marine Environment Protection Committee, which has determined limitations on the amount of sulfur in fuel that is acceptable for the sulfur emission control area (SECA). These limitations are too low to allow the use of high fuel oil in these SECAs. Therefore, marine diesel oil is used. It should be noted that a marine engine with a nominal power of $10 \mathrm{MW}$ consumes 48 tonnes of fuel per day (on the assumption that the specific fuel consumption is $200 \mathrm{~g} / \mathrm{kWh}$ ). Due to the significant air pollution and high costs of operating marine engines as a result of fuel consumption, engineers and scientists must improve the in-cylinder processes so that the combustion is cleaner and more efficient.

The combustion process in a diesel engine cylinder is mainly determined by the fuel injection process (Zhou et al., 2019). Fuel delivered by the injector is atomized and simultaneously evaporated, mixed with air/exhaust gas mixture and burnt. According to Payri et al. (2015), five phases may be observed in fuel tip propagation: non-reaction, auto-ignition expansion, stabilization, acceleration and quasi-steady propagation. The first phase is usually divided into two stages: primary and secondary breakup (Hiroyasu and Arai, 1990). Fuel is delivered and atomized to the cylinder under high pressure. The atomized fuel creates a cloud of droplets in a conical shape. The conical cloud of droplets is described by two main parameters: spray tip penetration (STP) and spray cone angle (SCA) (Figure 3) and micro-parameters such as Sauter mean diameter (SMD) or the average droplet diameter. It has been shown that these phenomena are determined by the dimensions of the fuel nozzle holes, the fuel flow, the pressure in the engine cylinder and the properties of the fuel.

In the literature, there are many studies, numerical and experimental, concerning the parameters of fuel injection depending on the injection pressure (Chen et al., 2019; Lei et al., 2019; Vaid et al., 2014), backpressure (ambient pressure in the engine cylinder) (Jing et al., 2017; Payri et al., 2009, 2017) and shape of the nozzle holes (Wang et al., 2015) including their conicity, which is defined by the $\mathrm{K}$ factor (Feng et al., 2016; Som et al., 2011), $K=1$ for cylindrical holes. According to results obtained by Payri et al. (2008), an increase of the $K$ factor causes an increase of the SCA. The method of fuel injector activation affects the parameters of the fuel spray as well. In Yu et al. (2017) and Suh et al. (2007), measurement results for piezo- and solenoid-driven fuel injectors were presented. The energizing of the fuel injector by a piezoelectric system with a fuel injection pressure of $60 \mathrm{MPa}$ causes lower tip penetration and a higher SCA than energizing by a solenoid system. An analysis of adjacent fuel injection holes (Nishida et al., 2009) is also available. Most research studies assume that the breakup process is determined by cavitation phenomena on the rough surfaces of the nozzle holes (Liu et al., 2018; Wang, 2013). Most research studies are limited to the injection process of the general diesel engine. Therefore, the injection system and fuel 
spray parameters of a marine diesel engine with the large nozzle length/diameter (L/D) with operating parameters the same as in a marine diesel engine is studied rarely. The cavitation phenomenon is important to design the criterion of the fuel injection system and spray characteristics in marine diesel engines.

Yan et al. (2016) studied the effect of injection pressure on cavitation and sprayed in marine diesel engines. This study was used to simulate cavitation and spray two-phase flow model combined with single bubble dynamics and a droplet breakup model. The numerical simulation results were compared with the experimental data. In the research of marine injectors, increasing development of numerical simulation tests is observed. Balz et al. (2021) present the numerical and experimental investigation of cavitation in marine diesel injectors. They showed that experimental in-nozzle flow visualization had shown cavitation patterns in the nozzle bore. It is determined that the geometric characteristics of nozzle bore location and its direction have a dominant effect on the type and evaluation of cavitation formation. The additional have been executed CFD simulation results in order to validate results. With the development of research on alternative fuels, there are a lot of studies on the characteristics of the fuel spray and combustion of fuels other than diesel (Adamczyk et al., 2020; Cai and Abraham, 2017; Yu, 2019).

It should be emphasized that the available publications concerning fuel injectors and injection conditions usually treat those occurring in diesel engines with small dimensions compared to marine engines (Kostas et al., 2009). According to Kowalski (2014), the diameter of the nozzle holes in marine fuel injectors is commonly larger than $0.3 \mathrm{~mm}$. The fuel injection pressure is similar at $40 \mathrm{MPa}$ (except for common rail systems), and the backpressure exceeds $4 \mathrm{MPa}$ at the instant of injection. The largest observed diameter of a nozzle hole $(0.3 \mathrm{~mm})$ is presented in Lee and Park (2002) but under higher fuel injection pressure. The parameters of the fuel spray are determined using mathematical models presented in the literature. The many developed models of diesel STP are elaborated based on the assumptions made by Hiroyasu and Arai (1990) or Naber and Siebers (1996). The fuel atomization model of Hiroyasu and Arai is used for the analysis of experimental research and the rating of the validity of their results. This model assumes that STP is linearly proportional to the time only in the early injection period. The values of the various spray parameters depend on time, ambient gas density, backpressures and differences in fuel specifications. After the period of time in which the STP has a linear proportionality, it has been found to be proportional to the square root of the elapsed time. In this period of time in which it is proportional to the square root of the elapsed time, geometrical parameters of the fuel nozzle, such as the diameter, must be taken into account. The other models of fuel STP described in the literature are similar to that of Hiroyasu and Arai and are in a general twostep (Bohl et al., 2017; Kostas et al., 2009) including $t_{B}$. According to these models, the initial step before $t_{B}$ does not include the geometrical parameters of the fuel nozzle. But usually, SCA and STP are measured for fully developed spray (Bohl et al., 2017; Hiroyasu and Arai, 1990; Reitz and Bracco, 1979). In a marine diesel engine, the start of combustion is much earlier (Kowalski, 2016). Hence, the present authors believe that the description of the early stage of fuel spray is most important to understand and describe the combustion process in the engine cylinder. The second novelty area, in comparison to other works, is the finding of dependence between the geometrical parameters of the fuel nozzle and the fuel spray geometry at the early stage of injection. This problem is omitted in the model of Hiroyasu and Arai and of others.

The main target of the present paper is to propose a new model of STP and SCA for large injectors. On the basis of experimental research, new models are proposed for the early stage
New model of fuel spray

2347 
HFF

32,7

2348

of fuel spray, taking into account the geometry of a large fuel injector. The model is obtained on the basis of experimental results and a modification of the Hiroyasu and Arai model.

\section{Laboratory setup}

The research was conducted in a constant volume chamber with a quartz window providing 100-mm optical access (Figure 1) (Grochowalska, 2019). The injector used is a conventional pressure-opened diesel injector from a Sulzer Al 25/30 type marine engine equipped with a unit pump injection system. The injector was located at the top of the chamber. This setup allows observing the evolution of a single fuel jet at a distance of almost $100 \mathrm{~mm}$ (half of the cylinder bore). The fuel was supplied to the injector by a high-pressure common rail system equipped with a fast-acting electromagnetic valve releasing fuel flow to the injector. The pressure behind the injector was measured by means of a Kistler type 4067E (Kistler, 2014) piezoresistive pressure sensor.

The spray inside the chamber was observed by means of the Mie scattering technique (Grochowalska, 2019; Piazzullo et al., 2017). The spray was illuminated in a visible range of wavelengths, as in Zigan et al. (2011). Mie scattering results may differ greatly depending on the type of spray illumination.

Light-sheet illumination is necessary when visualizing hollow cone sprays. As far as cylindrical nozzle sprays are concerned, the integral type of illumination performs very well, especially in the determination of global spray parameters. In this study, both SCA and STP were determined, and therefore, the integral illumination of the spray was chosen. For this purpose, two externally located halogen lights $(0.5 \mathrm{~kW}$ each) were used. The illuminated sprays were observed by a Photron SA1.1 high-speed camera. The resolution of the recorded images was $512 \times 256$ pixels. The images were recorded at a frequency of $40 \mathrm{kHz}$. A schematic of the experimental setup is shown in Figure 2.

The injection process was tested for three different nozzle diameters. The ratio $\frac{L}{D}(L$ is the length of the nozzle and $D$ is its diameter) is presented in Table 1 . The fuel pressure in the common rail system was $50 \mathrm{MPa}$. The injector opening pressure was adjusted to $25 \mathrm{MPa}$ (the same as in the $\mathrm{Al}$ 25/30 marine engine). Each nozzle was tested at two different backpressures: 3.2 and $4.3 \mathrm{MPa}$, corresponding to half- and full-load engine operation, respectively. The measurement was repeated three times at each point. The temperature during the test was $300 \mathrm{~K}$. The measured diesel oil viscosity and density were equal to 2.35

Figure 1.

Constant volume chamber with injector on the top

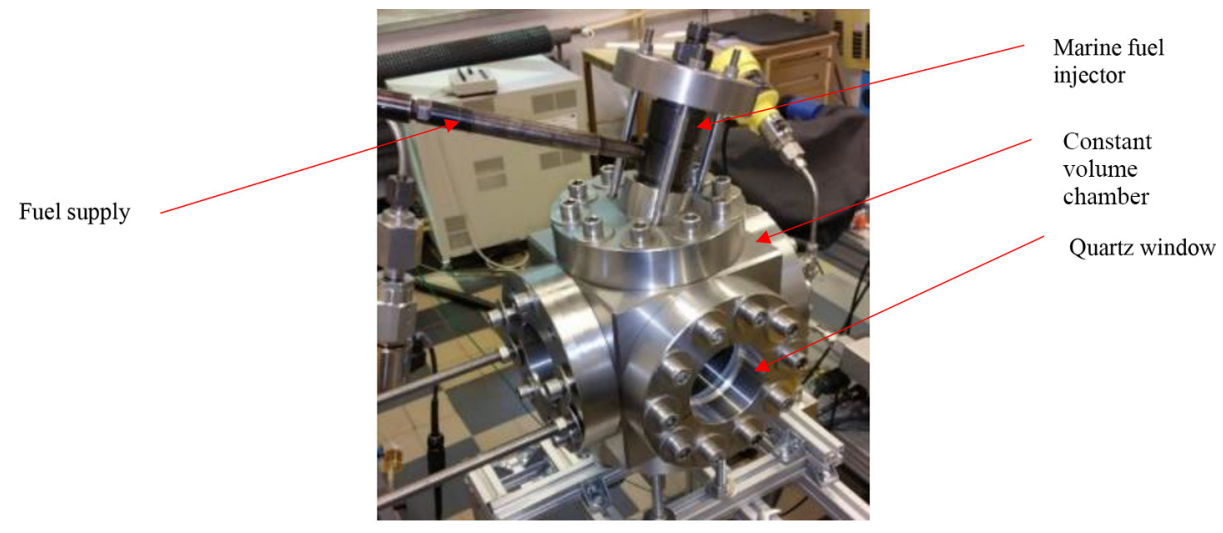

Source: Grochowalska (2019) 


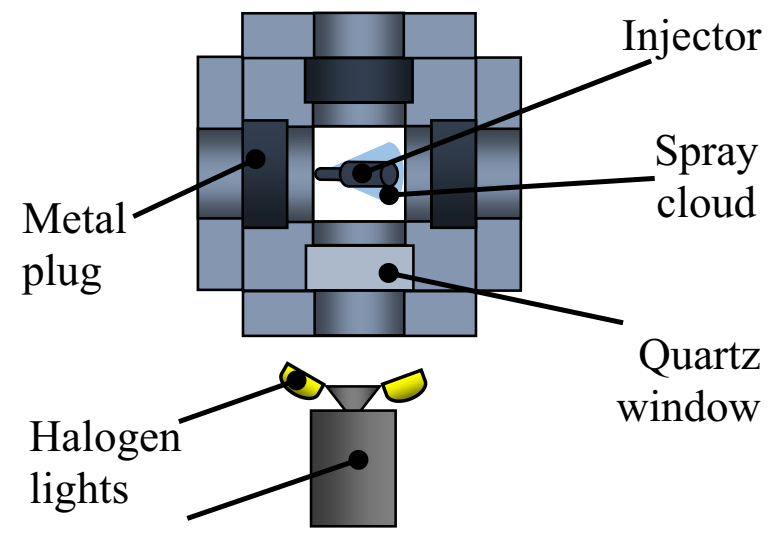

New model of fuel spray

Camera

Figure 2.

The experimental

setup

\begin{tabular}{lccc}
\hline & Diameter $(D)[\mu \mathrm{m}]$ & Ratio $\frac{L}{D}$ & K factor (Som et al., 2011) \\
\hline Nozzle 1 & 285 & 10.9 & 1 \\
Nozzle 2 & 325 & 9.5 & 1 \\
Nozzle 3 & 375 & 8.3 & 1 \\
\hline
\end{tabular}

Table 1.

Nozzle parameters

$\mathrm{mPa}$ and $816.1 \mathrm{~kg} / \mathrm{m}^{3}$, respectively, at $40^{\circ} \mathrm{C}$. The obtained images were processed by DaVis v8.4 software.

\section{Results and discussion}

Figure 3 presents an example of the resulting macro-parameters of the tested diesel spray. STP is defined as the distance from the nozzle to the front of the spray (Feng et al., 2016; Heywood, 1988). According to the presented results, the spray direction is determined by

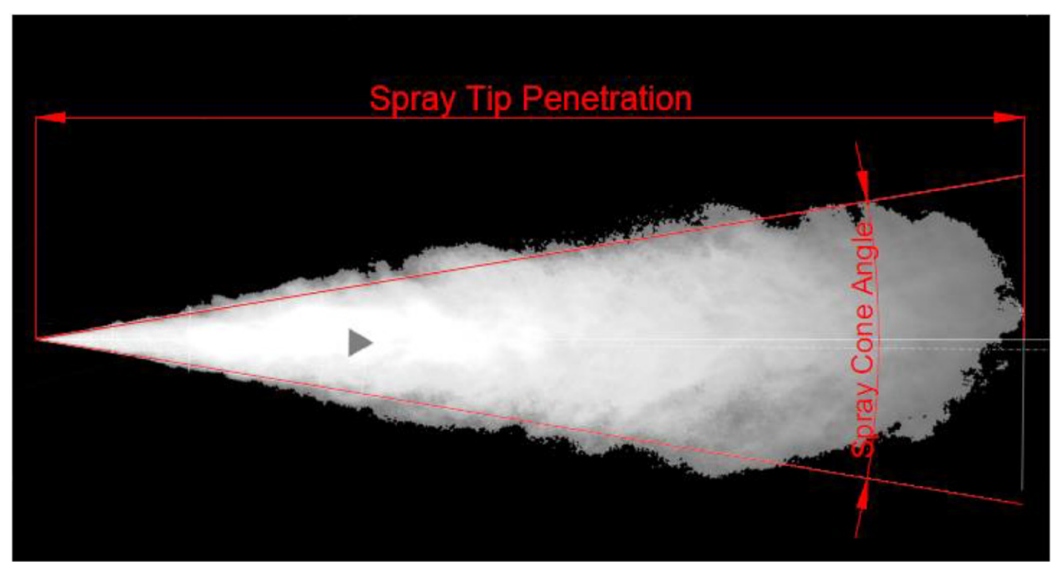

Figure 3. Schematic of diesel fuel spray defining its macro-parameters 
HFF

32,7

\section{0}

Figure 4.

Mie scattering spray image for Nozzle 2 with a backpressure of $4.3 \mathrm{MPa}$

\section{Figure 5.}

STP for the Nozzles 1, 2 and 3 with backpressures of $3.2 \mathrm{MPa}$ and $4.3 \mathrm{MPa}$ three lines: two on the boundaries on the left and right sides and the third being the line of the nozzle symmetry. Interpolation of the left and right sides of the boundary was performed.

The analysis of the macrostructure of the fuel spray was conducted using 250 frames for each injection process, which covered the range from the beginning of the injection to the complete development of the spray. Figure 4 shows selected images presenting the development of the diesel fuel spray for Nozzle 2 with a backpressure of $4.3 \mathrm{MPa}$. The measurements and received series of images depicting the diesel spray from the injector were recorded. Prior to the calculation of the macro-parameters of the diesel spray, pictures had to be prepared. The first stage of image processing was scaling from pixels to millimeters with verification of the nozzle position in the picture. One pixel is equal to $0.13 \mathrm{~mm}$ in this study. Second, the spray isolator function was used to separate the spray from the ambient and eliminate reflections and image noises within a short distance from the spray. The prepared series of images was used to define the STP and SCA and propose a new model for these parameters.

\subsection{Spray tip penetration}

Figure 5 presents the results of the STP measurements. These presented test results are the arithmetic mean of three observations of the measurement and are qualitatively similar to
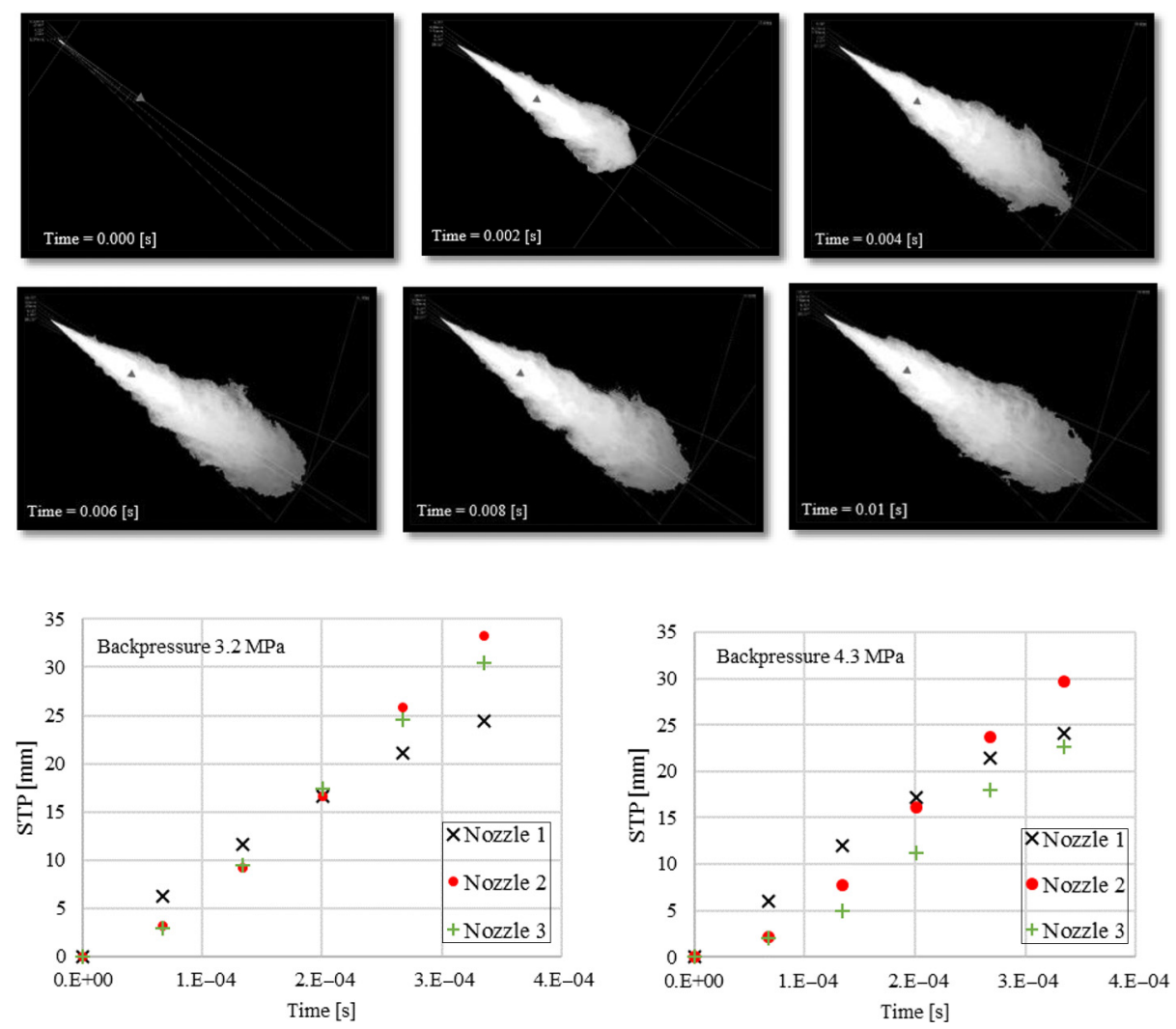
the results presented in Cai and Abraham (2017), Siebers (1999). Comparing these with the results of combustion in the AL25/30 engine from Kowalski (2014), it should be noted that the start of combustion is when the cloud of the fuel spray is not fully developed. These charts contain data only up to $0.0004 \mathrm{~s}$ (the cloud of the fuel spray is not fully developed). According to Siebers (1999), the maximum STP of fuel spray increases linearly with the increasing of nozzle diameter. This trend was observed in experimental results in the early stage of STP.

In the standard combustion chamber conditions, the maximum liquid spray distance is limited by hot air entrainment rate and mixing of fuel and air (Siebers, 1999). First of all, the energy needed for evaporation of the fuel results from the high ambient temperature in the cylinder of a diesel engine. The above evaporation is influenced by nozzle diameters, hot air entrainment rate and properties of the fuel. A decrease in the nozzle diameter causes a reduction of the size of the fuel droplets produced and lowers their speed. This finding was presented in the test results in Som et al. (2011). It is important to mention that decreasing $\frac{L}{D}$ (the increase of the nozzle diameter in this case) may cause a turbulent flow inside the nozzle and cavitation (Yao et al., 2016), which could also influence the results obtained here. Naturally, when the distance from the nozzle increases, the diameters of the droplets in the fuel spray decrease (Yu, 2019). As ambient gas density increases, spray dispersion increases, which results in more entrained air particles in the spray. The larger entrained mass leads to a slower penetration velocity based on conservation of momentum, and therefore, reduced penetration (Balz et al., 2020). This is caused by the aerodynamic resistance in the constant volume chamber (secondary breakup). The influence of increasing backpressure on reducing the STP was shown in Grochowalska (2019), Payri et al. (2017), Wang et al. (2016) and Yan et al. (2016) and are confirmed by the present results. On the basis of the analysis in Figure 5 and Grochowalska (2019), it may be concluded that an increase of backpressure generally causes a reduction of STP for big nozzles. The reason for this is the formation of large droplets at the exit of the fuel injector nozzle about the big diameter of the outlet nozzle. The large droplets not only break up longer in time under the influence of backpressure but also have a higher growth rate at the very beginning than the diameter droplets formation by the smaller diameter of the outlet nozzle. The higher growth rate of STP is shown in Figure 6. The growth rate of STP was particularly higher for a big nozzle at backpressure of $3.2 \mathrm{MPa}$ than at 4.3 $\mathrm{MPa}$. It should be noted that the working space of the constant volume chamber was filled with nitrogen. As is well known, nitrogen has a lower density than oxygen contained in the air. Therefore, the experimental results of STP are valid only for the considered condition.

3.1.1 Model for spray tip penetration. The temporal development of the STP in the combustion chamber of diesel engines has been examined and described for many years.
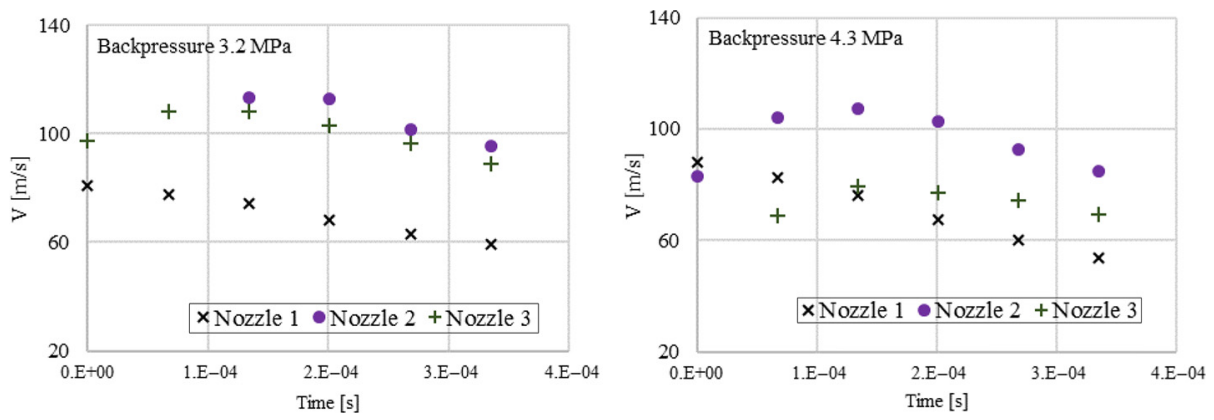

New model of fuel spray

2351

Figure 6. Growth rate of STP for backpressures of 3.2 $\mathrm{MPa}$ and $4.3 \mathrm{MPa}$ 
$\mathrm{HFF}$

32,7

2352

Generally, many correlations come from the work of Hiroyasu and Arai (1990). These correlations were used for comparison purposes in this paper. The Hiroyasu and Arai model was verified at low injection pressure and backpressure. Therefore, the theoretical correlations were believed appropriate in the analysis of the dependencies of the spray parameters of a marine diesel engine. Hiroyasu proposed that during the early stage of fuel injection, the spray penetration is proportional to time [linear stage (1)], whereas at later stages, it is proportional to the square root of the time (2). The time when the transition occurs is referred to as the breakup time $t_{b}$ (3). The Hiroyasu and Arai model is presented in the form:

$$
\begin{gathered}
\operatorname{STP}(t)=0.39 \sqrt{\left(\frac{2 \Delta P}{\rho_{f}}\right)} t \ldots 0<t<t_{b} \\
\operatorname{STP}(t)=2.95\left(\frac{\Delta P}{\rho_{f}}\right)^{\frac{1}{4}} \sqrt{(D t)} \ldots t>t_{b} \\
t_{b}=29 \frac{\rho_{f} D}{\left(\rho_{a} \Delta P\right)^{0.5}}
\end{gathered}
$$

STP $(\mathrm{t})$ - STP $(\mathrm{m}), \Delta P$ - the difference between fuel pressure in the nozzle and the ambient pressure $(\mathrm{Pa}), \rho_{f}$ - fuel density $\left(\mathrm{kg} / \mathrm{m}^{3}\right), D$ - nozzle diameter $(\mathrm{m}), t$ - time $(\mathrm{s})$.

According to the results presented in Figure 5, a linear model of STP may be adopted from the start of injection (SOI) to $(2.0-3.4) \times 10^{-4} \mathrm{~s}$, depending on the backpressure and nozzle diameter (time $t_{b}$ ). A smaller nozzle diameter and higher backpressure cause a decrease in $t_{b}$. According to the Hiroyasu and Arai model, the STP at the beginning of the injection does not depend on the nozzle diameter, but the measurement results show that this is not true. The initial stage of the experimental evolution of STP for all cases is very similar but not the same. Figure 5 shows the STP of the initial stage in the charts up to $0.0004 \mathrm{~s}$, in which it can be seen that there are differences, as depicted. Geometrical parameters such as the length to diameter ratio of the fuel nozzle have a significant effect on the STP in the considered nozzles. The influence of this ratio on liquid length spray penetration was found by Siebers (1999), who found a linear relation between the nozzle hole diameters and liquid spray penetration but only for fully developed fuel spray. The earlystage STP model of Hiroyasu and Arai does not include changes in the nozzle diameter, but only the difference between the fuel injection pressure and backpressure. As one of the main parameters of influence on the STP of fuel spray, there is a difference between the pressure into the nozzle and the backpressure in the constant volume chamber, which was included in the Hiroyasu and Arai model. Therefore, in the presented experimental tests, the fuel pressure in the fuel line was measured. The diesel fuel pressure was maintained by a fuel pump. The fuel pressure sensor was located in the fuel line in front of the fuel injector (Section 2). The fuel pressure before the exit nozzle is equal to the fuel line pressure. Opening the fuel injector caused fuel to flow and temporarily change the pressure in the fuel line to be the same as in the nozzle. At first, there follows a sharp rise in the fuel pressure, which then becomes stable. The temporary fuel pressure change in the fuel line and fuel spray propagation in the constant volume chamber continued simultaneously. In Lei et al. (2019), 
there was presented research about the effect of the injection behavior on fuel spray penetration, confirming the influence of the fuel pressure on the characteristics of the spray. Therefore pressure changes should be taken into consideration. Figure 7 presents the early stage of the experimental data of STP to time $0.0004 \mathrm{~ms}$ of the development of the fuel spray and the Hiroyasu and Arai model based on the experimental input data.

In Figure 7, there can be observed differences between the experimental results and the Hiroyasu and Arai model for the considered backpressures. The average relative error between the experimental results and the Hiroyasu and Arai model is in the range of 19\%$38 \%$ (Figure 9). Therefore, it can be suggested that a mathematical model of linear STP should be extended to include the influence of the nozzle diameters. The present analysis shows that equation (1) of the Hiroyasu and Arai model should be extended for the considered experimental results to the following form:

$$
S T P(t)=0.0641 \cdot\left(\frac{L}{D}+1\right) \sqrt{\left(\frac{2 \Delta P}{\rho_{f}}\right)} \cdot t
$$

ratio $\frac{L}{D}, L$ - nozzle length $[\mathrm{m}], D$ - nozzle diameter $[\mathrm{m}]$;

Examples of the results of the new model of the STP for Nozzle 1 are presented in Figure 8.
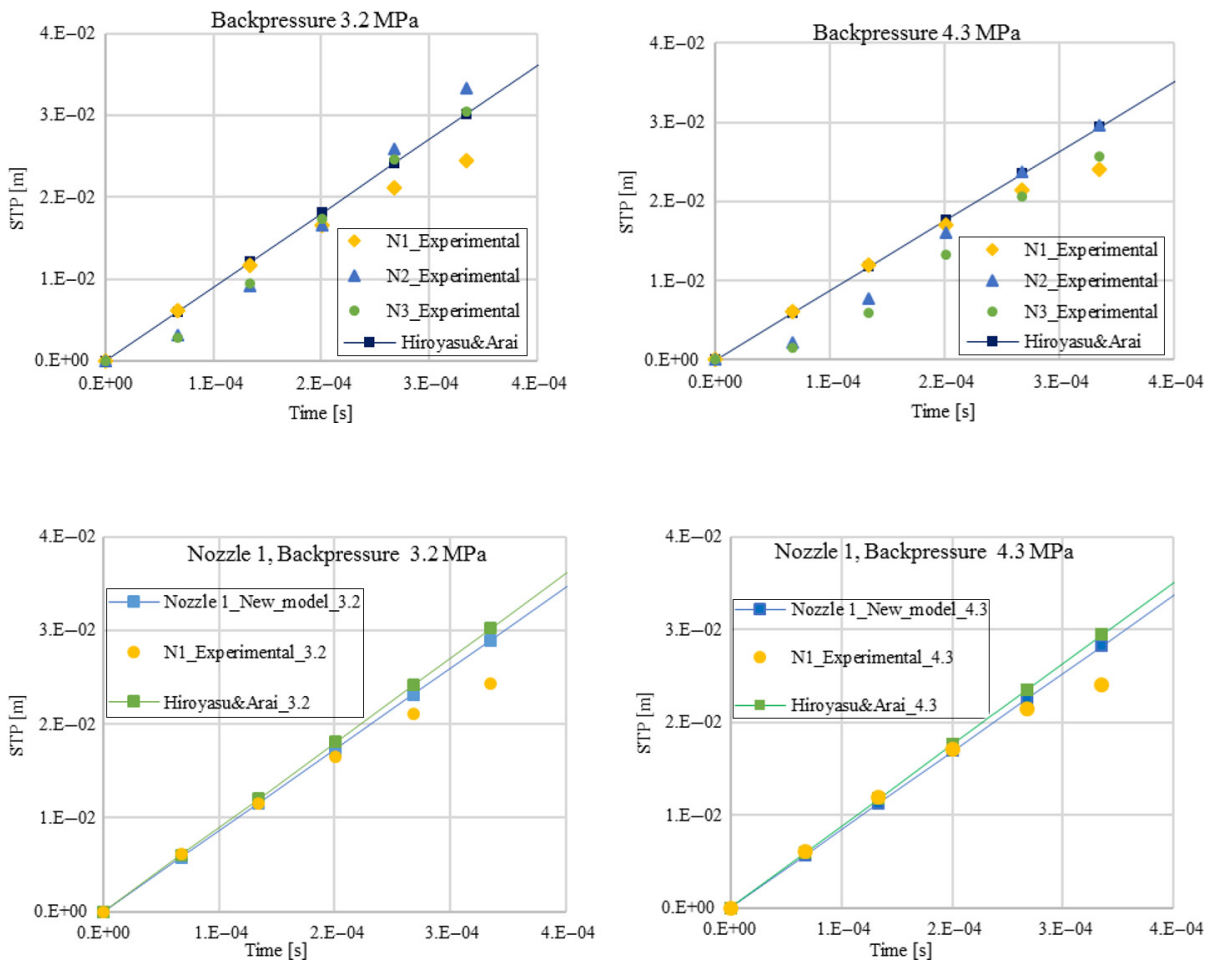

Figure 8.

Early stage of the STP for new model, experimental data and Hiroyasu and Arai model 
HFF

32,7

2354
Figure 9.

Average relative error between experimental of STP and new model of STP for all considered nozzles
Figure 10.

SCA for considered Nozzles 1,2, 3 and backpressures
The results of the modified model for STP agree with the experimental data. By introducing the ratio $\frac{L}{D}$, it is possible to adjust the model results to the experimental data for different nozzle geometries in the early stage of injection.

Figure 9 presents the calculated relative errors of the Hiroyasu and Arai model and the proposed STP model for the early stage of injection in comparison to the experimental results. A general analysis shows that the proposed model gives a lower average error in relation to the experimental results compared with the Hiroyasu and Arai model. The decrease of the mentioned error is about 15\%-34\% for the considered parameters in dependence on the fuel nozzle geometry.

\subsection{Spray cone angle}

Figure 10 presents the evolution of the SCA with time for the considered nozzles and backpressures. In the early stage (from the SOI up to $0.001 \mathrm{~s}$ ), the increase of the SCA can be observed for all of the tested nozzles. The value of the maximum SCA for diesel oil and different diameters of nozzles changes in a range of about $16^{\circ}-20^{\circ}$. Nevertheless, depending on the geometrical parameters of the injector nozzle, the growth rate of the SCA differs. When the nozzle diameter is increased and $\frac{L}{D}$ is decreased, it is possible to observe a decrease

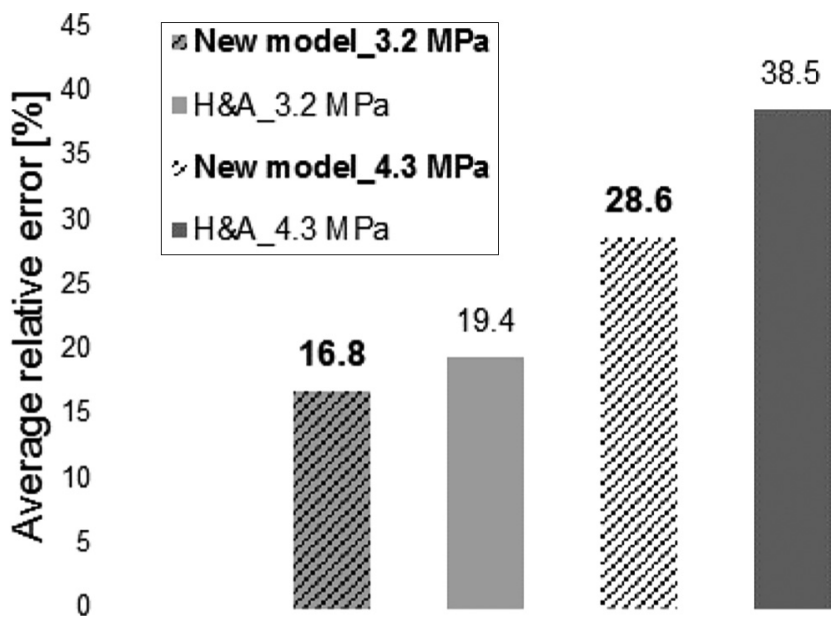

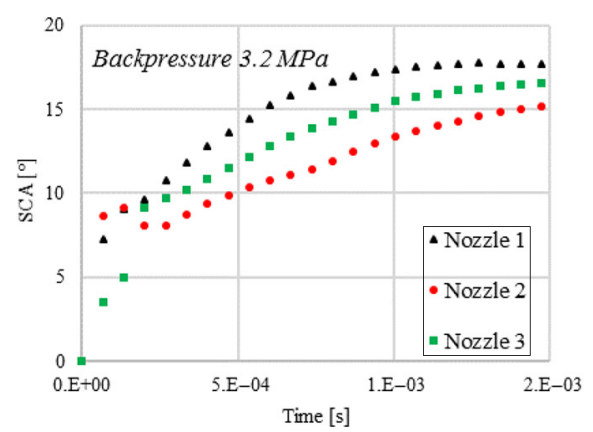

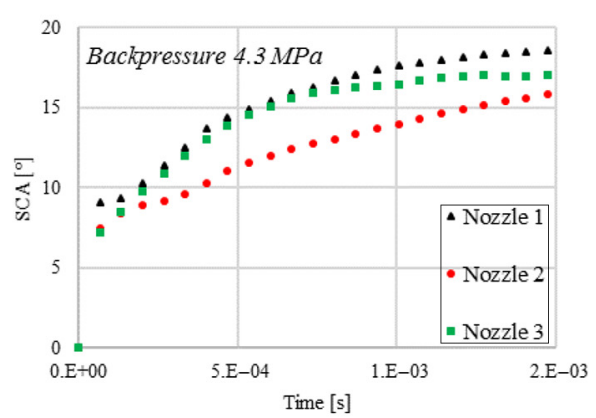


of the SCA at all considered backpressures, as shown in Figure 10. This is probably caused by the need for a longer time for the breakup and partial evaporation of the droplets produced by nozzles with bigger diameters.

The influence of the backpressure on the SCA was also observed. This is confirmed by Feng et al. (2016) and Figure 10. This is particularly observed for big nozzles of a fuel injector. An increased density of the surrounding gas causes a higher growth in the radial direction than in the axial one. As mentioned before, the difference between the fuel pressure and the backpressure influences the fuel spray. Therefore, Figure 11 shows the course over time of SCA in dependence on the difference between the injection pressure of the fuel injector and the backpressure into the constant volume chamber $(\Delta P)$. It should be noted that the injection pressure was changed in time, but the backpressure was almost constant.

Additionally, the value of the SCA may be influenced by cavitation occurring at the end of the nozzle (Balz et al., 2020). The formation of cavitation bubbles at the exit of the nozzle may cause greater dissipation and an increase in the value of the SCA (Sou et al, 2007). For Nozzles 2 and 3, there was observed a significant effect of a change in the difference between the pressures on the SCA in time (Grochowalska, 2019). This is related to the formation of large droplets in the fuel spray at the beginning and the aerodynamic resistance in the constant volume chamber. An increase of backpressure in the constant volume chamber caused a decrease in the influence of the difference between the pressures on SCA for Nozzles 2 and 3.

Generalizing this observation, a change in the fuel pressure in the fuel line over time in relation to the backpressure on the exit injection nozzle has an influence on the SCA. This influence on the SCA decreases over time. The second observation is that an increase of the backpressure on the exit of the fuel nozzle causes a decrease in the influence of the pressure change on the value of the SCA over time.

3.2.1 Model for the spray cone angle. The existing mathematical models for SCA represent constant angles throughout the whole time of the development of the spray (Heywood, 1988; Kegl and Lešnik, 2018; Reitz and Bracco, 1979). The models in the literature include some characteristics of the nozzle and parameters of the injection process, fuel properties and spray environmental conditions. In the present paper, the Hiroyasu and Arai model of the SCA was selected for comparison with the experimental data. That model was presented in equation (5), and Table 2 presents the SCA for the experimental and calculated results.

$$
S C A=83.5\left(\frac{L}{D}\right)^{-0.22} \cdot\left(\frac{D_{0}}{D_{s a c}}\right)^{0.15} \cdot\left(\frac{\rho_{g}}{\rho_{f}}\right)^{0.26}
$$

where: $D_{s a c}$ - the diameter of injector sac.
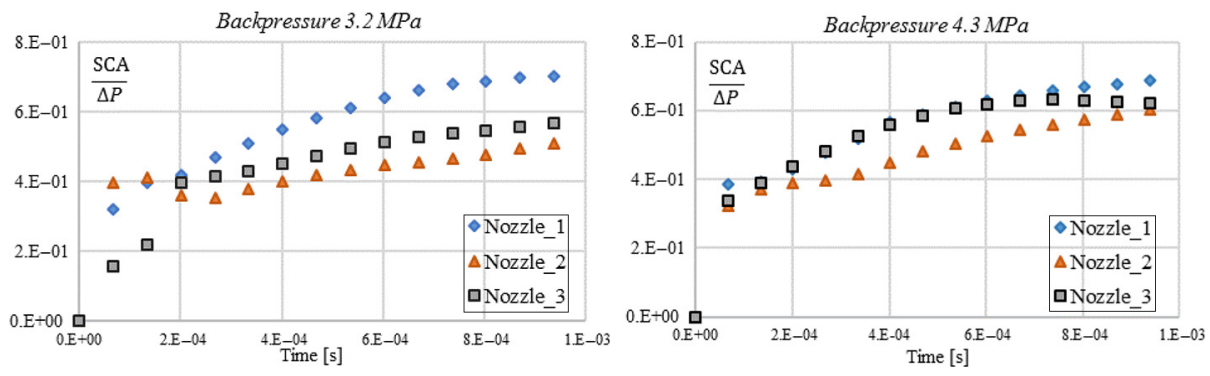

New model of fuel spray

2355 
HFF

32,7

2356

The experimental SCA for the considered large nozzles was higher than results from the Hiroyasu and Arai model. Autoignition of the air-fuel mixture in the cylinder of the marine engine occurs when the fuel spray does not reach its maximum development parameters. Therefore, it is important to develop a model of the change in the SCA over time. The first five measurements of SCA were omitted from the analysis because of their great dispersion, probably caused by measurement inaccuracy. The mentioned measurements results have a large error because of the difficulties in processing the photographic results. The SCA at the beginning of the course at the time was difficult to estimate. The proposed model presented in this paper equation (6) was developed on the basis of dependencies defined by combining terms from existing models. When analyzing the experimental results, one can notice the logarithmic function of the early stage of the evolution of the SCA over time.

Using this as the basis, the following proposed model of SCA was formulated:

$$
S C A=\left[-0.462 \cdot \frac{L}{D}+\sqrt{\Delta P} \cdot\left(\frac{\rho_{f}}{\rho_{g}}\right)^{0.2}\right] \ln (t)+(3.17 \cdot \Delta P-28.067),
$$

By analyzing all considered cases, the average of relative error of the proposed model of SCA over time is $20 \%$ for backpressure $3.2 \mathrm{MPa}$ and $17 \%$ for backpressure $4.3 \mathrm{MPa}$.

\section{Conclusions}

The macrostructure of diesel oil spray from a marine engine injector was characterized using the Mie scattering method. The parameters that were measured were the STP and the SCA. These parameters were analyzed in terms of three different nozzle diameters and two backpressures, 3.2 and 4.3 MPa, corresponding to engine operation under half and full loads, respectively. The main theories concerning the influence of the geometric parameters of the injector nozzle on STP and SCA were confirmed:

- increasing the diameter $\mathrm{D}$ of the injector nozzle or decreasing the ratio $\frac{L}{D}$ (where $L$ is the length of the nozzle) increases the STP and SCA; and

- changing the backpressure from 3.2 to $4.3 \mathrm{MPa}$ decreases the STP and increases the SCA.

The early stage of STP was described based on the Hiroyasu and Arai model. But the proposed model also includes a dependence on $\frac{L}{D}$. Additionally, a model for SCA was developed, which assumes a logarithmic dependence of the SCA on time. The average of relative error of the proposed model from the experimental results was about $18 \%$. The new mathematical models of the fuel spray parameters used in this work were obtained on the basis of experimental work with specific conditions. Therefore, the mathematical models of SCA and early STP are specified for specific conditions such as the geometrical parameters of a marine injector, the injection pressure and the backpressure into a constant volume chamber.

Table. 2

Backpressure 3.2 MPa Experimental

Experimental

$\mathrm{SCA}\left[{ }^{\circ}\right]$ by Hiroyasu and Arai model and experimental data (H\&A model) Average 3.2 MPa Backpressure 4.3 MPa (H\&A model) Average $4.3 \mathrm{MPa}$

\begin{tabular}{lcccc} 
Nozzle & (H\&A model) & Average 3.2 MPa & Backpressure 4.3 MPa (H\&A model) & Average 4.3 MPa \\
\hline 1 & 12.97 & 17 & 14.00 & 19 \\
2 & 13.63 & 16 & 14.71 & 18 \\
3 & 14.34 & 17 & 15.49 & 17 \\
\hline
\end{tabular}




\section{References}

Adamczyk, W.P., Kruczek, G., Bialecki, R. and Przybyła, G. (2020), "Application of different numerical models capable to simulate combustion of alternative fuels in internal combustion engine", International Journal of Numerical Methods for Heat and Fluid Flow, Vol. 30 No. 5, pp. 2517-2534.

Balz, R., von Rotz, B. and Sedarsky, D. (2020), "In-nozzle flow and spray characteristics of large twostroke marine diesel fuel injectors", Applied Thermal Engineering, Vol. 180 No. June, p. 115809.

Balz, R., Nagy, I.G., Weisser, G. and Sedarsky, D. (2021), "Experimental and numerical investigation of fuel spray cavitation in marine diesel injectors", International Journal of Heat and Mass Transfer, Vol. 169, doi: 10.1016/j.ijheatmasstransfer.2021.120933.

Bohl, T., Tian, G. and Smallbone, A. (2017), "Macroscopic spray characteristics of next-generation bioderived diesel fuels in comparison to mineral diesel”, Applied Energy, Vol. 186, pp. 562-573.

Cai, G. and Abraham, J. (2017), "Multidimensional simulations of non-reacting and reacting diesel and biodiesel sprays", Energy, Vol. 119, pp. 1221-1229.

Chen, L., Li, G., Huang, D., Zhang, Z., Lu, Y., Yu, X. and Roskilly, A.P. (2019), "Experimental and numerical study on the initial tip structure evolution of diesel fuel spray under various injection and ambient pressures", Energy, Vol. 186, p. 115867.

Feng, Z., Zhan, C., Tang, C., Yang, K. and Huang, Z. (2016), "Experimental investigation on spray and atomization characteristics of diesel/gasoline/ethanol blends in high pressure common rail injection system”, Energy, Vol. 112, pp. 549-561.

Grochowalska, J. (2019), "Analysis of the macrostructure of the fuel spray atomized with marine engine injector”, Combustion Engines, Vol. 179 No. 4, pp. 80-85.

Heywood, J.B. (1988), "Internal Combustion Engine Fundementals", McGrawHill Series in Mechanical Engineering, Vol. 21, ISBN: 0-07-028637-X.

Hiroyasu, H. and Arai, M. (1990), "Structures of fuel sprays in diesel engines", SAE Technical Paper.

Jing, D., Zhang, F., Li, Y., Xu, H. and Shuai, S. (2017), "Experimental investigation on the macroscopic and microscopic spray characteristics of dieseline fuel", Fuel, Vol. 199, pp. 478-487.

Kegl, B. and Lešnik, L. (2018), "Modeling of macroscopic mineral diesel and biodiesel spray characteristics", Fuel, Vol. 222, pp. 810-820.

Kistler (2014), "Piezoresistive high pressure sensor", available at: www.kistler.com/?type=669\&fid= $61054 \&$ model=document $\&$ callee $=$ frontend

Kostas, J., Honnery, D. and Soria, J. (2009), "Time resolved measurements of the initial stages of fuel spray penetration", Fuel, Vol. 88 No. 11, pp. 2225-2237.

Kowalski, J. (2014), "An experimental study of emission and combustion characteristics of marine diesel engine with fuel pump malfunctions", Applied Thermal Engineering, Vol. 65 Nos 1/2, pp. 469-476.

Kowalski, J. (2016), "An experimental study of emission and combustion characteristics of marine diesel engine with fuel injector malfunctions", Polish Maritime Research, Vol. 23 No. 1, pp. 77-84.

Lee, C.S. and Park, S.W. (2002), "An experimental and numerical study on fuel atomization characteristics of high-pressure diesel injection sprays", Fuel, Vol. 81 No. 18, pp. 2417-2423.

Lei, Y., Liu, J., Qiu, T., Mi, J., Liu, X. and Zhao, N. (2019), "Effect of injection dynamic behavior on fuel spray penetration of common-rail injector”, Energy, Vol. 188, p. 116060.

Liu, F., Li, Z., Wang, Z., Dai, X., He, X. and Lee, C. (2018), "Microscopic study on diesel spray under cavitating conditions by injecting fuel into water", Applied Energy, Vol. 230 No. October 2017, pp. 1172-1181.

Naber, J. and Siebers, D.L. (1996), "Effects of gas density and vaporization on penetration and dispersion of diesel sprays", No. 412, doi: 10.4271/960034. 
Nishida, K., Tian, J., Sumoto, Y., Long, W., Sato, K. and Yamakawa, M. (2009), “An experimental and numerical study on sprays injected from two-hole nozzles for DISI engines", Fuel, Vol. 88 No. 9, pp. 1634-1642.

Payri, R., García-Oliver, J.M., Xuan, T. and Bardi, M. (2015), "A study on diesel spray tip penetration and radial expansion under reacting conditions", Applied Thermal Engineering, Vol. 90, pp. 619-629.

Payri, R., Salvador, F.J., Gimeno, J. and de la Morena, J. (2009), "Effects of nozzle geometry on direct injection diesel engine combustion process", Applied Thermal Engineering, Vol. 29 No. 10, pp. 2051-2060.

Payri, R., Tormos, B., Salvador, F.J. and Araneo, L. (2008), "Spray droplet velocity characterization for convergent nozzles with three different diameters”, Fuel, Vol. 87 Nos 15/16, pp. 3176-3182.

Payri, R., Viera, J.P., Gopalakrishnan, V. and Szymkowicz, P.G. (2017), "The effect of nozzle geometry over the evaporative spray formation for three different fuels", Fuel, Vol. 188, pp. 645-660.

Piazzullo, D., Costa, M., Allocca, L., Montanaro, A. and Rocco, V. (2017), "Schlieren and Mie scattering techniques for the ECN 'spray G' characterization and 3D CFD model validation”, International Journal of Numerical Methods for Heat and Fluid Flow, Vol. 28 No. 2, pp. 498-515.

Reitz, R.D. and Bracco, F.B. (1979), "On the dependence of spray angle and other spray parameters on nozzle design and operating conditions”, SAE technical paper, doi: 10.4271/790494.

Siebers, D.L. (1999), "Scaling liquid-phase fuel penetration in diesel sprays based on mixing-limited vaporization", SAE Technical Papers, No. 724, doi: 10.4271/1999-01-0528.

Som, S., Ramirez, A.I., Longman, D.E. and Aggarwal, S.K. (2011), "Effect of nozzle orifice geometry on spray, combustion, and emission characteristics under diesel engine conditions", Fuel, Vol. 90 No. 3, pp. 1267-1276.

Sou, A., Hosokawa, S. and Tomiyama, A. (2007), "Effects of cavitation in a nozzle on liquid jet atomization", International Journal of Heat and Mass Transfer, Vol. 50 Nos 17/18, pp. 3575-3582.

Suh, H.K., Park, S.W. and Lee, C.S. (2007), "Effect of piezo-driven injection system on the macroscopic and microscopic atomization characteristics of diesel fuel spray", Fuel, Vol. 86 Nos 17/18, pp. 2833-2845.

Vaid, H.S., Singh, K.D., Lou, H.H., Chen, D. and Richmond, P. (2014), "A run time combustion zoning technique towards the EDC approach in large-scale CFD simulations", International Journal of Numerical Methods for Heat and Fluid Flow, Vol. 24 No. 1, pp. 21-35.

Wang, X. (2013), "A phenomenological bubble number density model developed for simulation of cavitating flows inside high-pressure diesel injection nozzles", International Journal of Numerical Methods for Heat and Fluid Flow, Vol. 23 No. 8, pp. 1356-1372.

Wang, Z., Ding, H., Ma, X., Xu, H. and Wyszynski, M.L. (2016), "Ultra-high speed imaging study of the diesel spray close to the injector tip at the initial opening stage with single injection”, Applied Energy, Vol. 165, pp. 335-344.

Wang, X., Wang, X., Zhang, J. and Wang, J. (2015), "Nozzle diameter influence on spraycharacteristics in a constant volume combustion chamber", Mathematical Modelling of Engineering Problems, Vol. 2 No. 3, pp. 9-12.

Yan, F., Du, Y., Wang, L., Tang, W., Zhang, J., Liu, B. and Liu, C. (2016), "Effects of injection pressure on cavitation and spray in marine diesel engine", International Journal of Spray and Combustion Dynamics, Vol. 0 No. 2, pp. 1-13.

Yao, C., Geng, P., Yin, Z., Hu, J., Chen, D. and Ju, Y. (2016), "Impacts of nozzle geometry on spray combustion of high pressure common rail injectors in a constant volume combustion chamber", Fuel, Vol. 179, pp. 235-245.

Yu, Y. (2019), "Experimental study on effects of ethanol-diesel fuel blended on spray characteristics under ultra-high injection pressure up to $350 \mathrm{MPa}$ ", Energy, Vol. 186, p. 115768. 
Yu, W., Yang, W., Mohan, B., Tay, K.L. and Zhao, F. (2017), "Macroscopic spray characteristics of wide distillation fuel (WDF)", Applied Energy, Vol. 185, pp. 1372-1382.

Zhou, X., Li, T., Wei, Y. and Wu, S. (2019), "Scaling spray combustion processes in marine low-speed diesel engines", Fuel, Vol. 258 No. September, p. 116133.

Zigan, L., Schmitz, I., Flügel, A., Wensing, M. and Leipertz, A. (2011), "Structure of evaporating singleand multicomponent fuel sprays for 2nd generation gasoline direct injection”, Fuel, Vol. 90 No. 1, pp. 348-363.

\section{Corresponding author}

Joanna Grochowalska can be contacted at: joanna.lewinska@pg.edu.pl
New model of fuel spray

For instructions on how to order reprints of this article, please visit our website: www.emeraldgrouppublishing.com/licensing/reprints.htm Or contact us for further details: permissions@emeraldinsight.com 